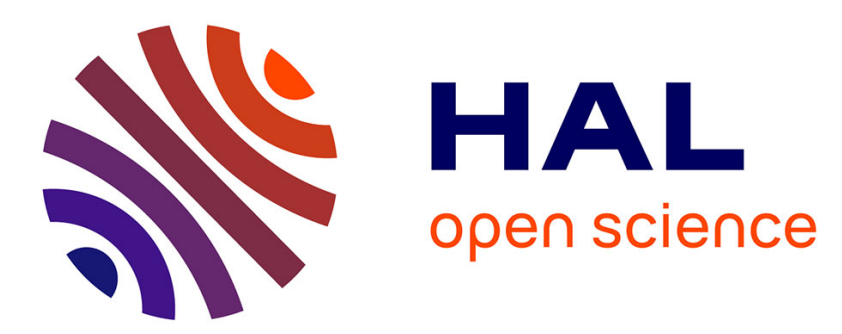

\title{
Collaborative ICT ventures and the implementation of responsive automotive supply networks
}

\author{
Gareth Stone, Mickey Howard, Joe Miemczyk, Andrew Graves
}

\section{To cite this version:}

Gareth Stone, Mickey Howard, Joe Miemczyk, Andrew Graves. Collaborative ICT ventures and the implementation of responsive automotive supply networks. International Journal of Automotive Technology and Management, 2008, 8 (3), pp.239-253. 10.1504/IJATM.2008.020211 . hal-00765391

\author{
HAL Id: hal-00765391 \\ https://hal.science/hal-00765391
}

Submitted on 23 Feb 2015

HAL is a multi-disciplinary open access archive for the deposit and dissemination of scientific research documents, whether they are published or not. The documents may come from teaching and research institutions in France or abroad, or from public or private research centers.
L'archive ouverte pluridisciplinaire HAL, est destinée au dépôt et à la diffusion de documents scientifiques de niveau recherche, publiés ou non, émanant des établissements d'enseignement et de recherche français ou étrangers, des laboratoires publics ou privés. 
Collaborative ICT Ventures and the Implementation of Responsive Automotive Supply Networks

\title{
Gareth Stone
}

ILIPT, University of Bath

Bath, BA2 7AY

E-mail: G.M.Stone@bath.ac.uk

+44 (0) 1225383967

\section{Mickey Howard}

Operations and Supply Group

School of Management, University of Bath

Bath, BA2 7AY

E-mail: M.B.Howard@bath.ac.uk

+44 (0)1225383682

Joe Miemczyk

Audencia, Ecole De Management, Nantes

Nantes, France

E-mail:jmiemczyk@audencia.com

\section{Andrew Graves}

School of Management, University of Bath

Bath, BA2 7AY

E-mail:A.P.Graves@bath.ac.uk

\begin{abstract}
This research paper explores the generic barriers which govern supply chain integration. Four automotive cases illustrate the motivations and barriers that emerged during the implementation phase of collaborative ICT ventures. The results indicate the reasons for failure of ICT as the solution to collaborative supply chain integration. We show that ICT in relation to supply chain collaboration (SCC) is still at an embryonic stage of development. Recent examples of ebusiness initiatives are used to develop further a framework of barriers for supply chain integration and collaboration based in the automotive sector. The barriers to successful integration and collaboration identified in this research include system standards, legacy systems and interoperability, cost-benefit sharing, and interorganizational trust. The paper concludes by suggesting that for ICT ventures to be successful in achieving requirements, inter-firm relationships must be a first consideration, certainly before implementing technology.
\end{abstract}

Keywords: information communication technology, supply chain collaboration, implementation, barriers, responsiveness 
Reference to this paper should be made as follows: Stone, G., Howard, M., Miemczyk, J. and Graves, G. (2006/7) Collaborative ICT Ventures and the Implementation of Responsive Automotive Supply Networks, Int. J. AutomotiveTechnology and Management, Vol.

Biographical notes: Gareth Stone joined the School of Management, University of Bath in 2001 after gaining a broad industrial background in the Aerospace industry. $\mathrm{He}$ is involved with the European Commission funded Automotive programme ILIPT (Intellegent Logistics for Innovative Product Technologies). Gareth has lectured in operations management at Southampton Business School and has recently been involved with a 3 year Aerospace research programme UKLAI, (UK Lean Aerospace Initiative) which is partnered with MIT and focused on the implementation of lean processes within the UK Aerospace Industry.

Mickey Howard is a Senior Lecturer in Operations Management at the School of Management, University of Bath. Prior to this he worked for 10 years as a product designer of thermoplastic components in the automotive and retail sectors. His career as an academic began at the University of Bath in 1999 as a research officer for the '3Daycar' programme, which examined build-to-order in the automotive industry. His current research focuses on technology \& innovation management, and the implementation of responsive supply strategy.

Joe Miemczyk is Assistant Professor in Supply Chain Management at Audencia, Nantes, France. Previously, he has worked on the 3DayCar programme and was most recently theme leader on the European ILIPT project. Joe has published widely on in the area of automotive logistics and has presented at a number of conferences in operations management, logistics and environmental management.

Andrew Graves is Professor of Technology Management at The University of Bath and directs research into Lean Manufacturing and Agile Production within the IMRC (Innovative Manufacturing Research Centre). He is a mechanical engineer and political scientist and began his industrial career as a trainee manager with the Rootes Group in 1966. At the Science Policy Research Unit at the University of Sussex he undertook research with MIT's IMPV (International Motor Vehicle Programme) on R\&D and technology issues and subsequently became European Programme Director to the programme.

\section{$1 \quad$ Customer demand and collaborative leadership}

The failure of several high profile Collaborative Planning Forecasting and Replenishment (CPFR) implementations suggest that supply chain integration is still only a promise in more traditional manufacturing sectors such as automotive. Despite considerable efforts by OEMs and suppliers through initiatives such as Covisint, there are few signs of true customer demand responsiveness and collaborative supply chains based on joint decision making. Despite the existence of success stories (Smith, 2006), this is a surprising revelation, particularly given the coverage in academic and trade press regarding the perceived benefits of information sharing through web-enabled CPFR.

Attempts to adopt a joint planning and decision-making strategy have been largely unsuccessful to date. Stank et al, (1999) failed to verify the existence of even broad based performance enhancements related to the implementation of CPFR even though they conceded that overall costs could be reduced. Barriers such as industry structure, silo management and product complexity inherent in the supply network all impact on managers' ability to implement collaborative planning systems which enable synchronisation of responsive demand across automotive supply networks.

Much has been made of the benefits accrued by firms in the FMCG, computer, and retail sectors adopting ICT to boost competitiveness through responsive inter- 
organisational demand management (i.e. Tesco, Dell, Zara). The automotive industry OEMs have also made significant strides to reduce the order fulfilment cycle using ICT to connect limited areas of the supply network, e.g. component manufacture with vehicle assembly, and vehicle distribution with dealer sales. The industry constantly looks to new frontiers to achieve competitive advantage at a time when over-capacities and eroded profits threaten firms' very existence, for example by following the commonly stated goal to only build vehicles to customer demand. While the argument for shifting away from make-to-stock towards a locate-to-order and build-to-order approach is well established (Holweg, 2005), the success factors governing implementation of interorganizational information systems are neither clear in the literature nor widely disseminated. This is astonishing when the industry depends on the manufacture and distribution of goods which require the synchronisation of hundreds of supply partners, thousands of components, and millions of potential product variants per customer order.

\section{Literature review: ICT and inter-organizational IS adoption}

The role of ICT across industry supply chains has traditionally focused on the fields of economics, co-ordination, and competition (Clemons, 1992; Konsynski, 1990; Porter, 1985). Economic benefits are related to the reduction in transmission charges and administrative costs, such as $\$ 200$ million savings by the Chrysler Corporation (Mukhopadyay, 1995). Co-ordination benefits arise from the tight coupling and speed of exchanging information leading to efficiencies between firms such as reduced inventory Stank et al, 1999). Competitive advantage stems from gaining access through ICT to diversified markets and leveraging key resources in new areas using economies of scale and scope (Porter \& Miller, 1985)

The adoption of information systems not only changes the way a firm competes, but also enables technology to be used as a 'competitive weapon' against other firms Ives \& Learmonth, 1984). Webster (1995) provides a classic description of this phenomenon in the automotive industry. The case reveals the high costs of investing in bespoke EDI at the time and which is used as a competitive weapon to preserve the power of dominant stakeholders i.e. the vehicle manufacturer, thereby locking suppliers into procurement relationships and keeping competitors out of them.

An alternative perspective to ICT as a competitive weapon is an enabler of cooperation that provides a stable platform for inter-organizational collaboration. Ciborra (1993) proposes reforms of the relationships with suppliers, customers and other partners based on a mix of organizational forms: teams, markets and hierarchies where technology can be harnessed to shape businesses and increase market transparency.

Supply chain relationships today have, generally speaking, advanced from competitive to collaborative (Bowersox \& Closs, 1996). This is reflected by a shift in inter-organizational systems literature in the 1990s that describes the role of information technology as 'enabling the transition from inter-firm competition to cooperation' (Kumar \& van Dissel, 1996). These are described as information and communication technology systems that transcend legal enterprise boundaries and imply a high level of cooperation and coordination. Their classification of system types identifies the arguments for potential conflict and hence possible strategies for containing conflict. Similarly, Hart \& Saunders (1997) study electronic relationships between organizations, particularly the role of power and trust in EDI adoption. They posit computer networks are increasingly adopted to support the flow of information with 'their use both influencing and having consequence for inter-organizational relationships'. 
It is often argued that ICT will reshape the automotive industry. True, the car business is ripe for revolution being poorly equipped to thrive in the 21 st century and with chronic debt and overcapacity problems, where '...about half of the industry is regularly incapable of earning a decent return on its invested capital' Economist (2004a). Yet several false summits have already been encountered. First, the arrival of Enterprise Resource Planning (ERP) in the 1990's has not proved as successful as first anticipated, with around half of customers across all sectors believing they paid more than the system was worth (Vance, 2003). Second, the promise of the e-commerce revolution, driven by visions of virtual organizations and the digital economy (Lapidus, 2000; Tapscot et al., 2000), is taking longer to materialise than expected. Despite optimism in business-to-customer (B2C) systems in sectors such as retail, groceries, and music (Economist, 2004b), the adoption of business-to-business (B2B) systems by firms in traditional manufacturing industries such as automotive face considerable barriers (Howard et al, 2006).

In summary, barriers research can be traced to early inter-organizational systems (IOS) literature that considers the interchange of information as the basis of all activity Barret \& Konsynski 1982). In their assessment of the impact of IOS Barret and Konsynski describe 'factors of concern' as how new technologies are introduced into the firm and the resultant effects on organizational structure, users, and the IT department. Early attempts to unify the fragmented models of information system implementation reveal five categories of factor: individual, structural, technological, task-related, and environmental (Kwon \& Zmud, 1987). Hence, planning for IOS-related change requires clear strategic objectives and a systematic means of identifying project constraints, barriers, or features (Earl, 1989). Even today the planning, implementation, and maintenance of an e-procurement programme across supply chains represents a considerable challenge (Presutti, 2003). This situation is exacerbated by automotive industry stakeholders facing a whole range of different barriers to effective change internally and across the supply chain (Howard et al., 2006).

\subsection{Supply responsiveness}

Supply responsiveness can be thought of in two ways. The first deals with how supply chains respond to raw market demand signals. Many automotive manufacturers strive to meet customer expectations through build to order. Supply chains are being engineered to cope with real demands rather than forecast based production. The alternative perspective sees supply chains as needing to deal with fluctuating demand resulting from managerial interventions and incompatible planning and information systems. Responsiveness in the supply base is needed for both these scenarios.

Fisher (1997) distinguishes between supply chains that are market responsive and those that are physically efficient. The former is aimed at a quick response to unpredictable demand and thus requires high supply chain flexibility. This concept is also specified by Christopher (1999) as agility, whereby agility should be obtained through the integration of other elements of the supply chain such as external suppliers. Supply responsiveness, in an automotive context, has been defined as "the ability of a manufacturing system or organisation to adapt to changes and requests in the marketplace" (Holweg, 2005). In order to gain increased supplier responsiveness some authors claim that automotive companies require co-location, single sourcing, selection based on flexibility, internal collaboration (between purchasing and production) and integration with logistics providers (Tachizawa, 2005). Other sources state process flexibility, e.g. the ability to change schedules on a frequent basis is necessary 
(Krajewski, 2005) and information system flexibility "the ability to align information system architectures with the changing information needs of the organisation as it responds to changing customer demand" (Duclos, 2003). Not only do supply chains have to deal with changing demands from the market, but the lack of timely and accurate information exchange causes its own problems. For example, this leads to one of the key topics in supply chain management: the bullwhip effect.

Lee (1997) explains that demand is often amplified up the supply chain due to the way that orders are processed and passed on by each link in that chain. One of the main causes of this effect is demand forecast updating, whereby demand planning information is passed only sequentially up the supply chain, creating large swings in expected demand further upstream. The authors suggest that there are a number of actions that can reduce the bullwhip effect including using Point Of Sale (POS) data, sharing sales, capacity and inventory information, and Vendor Managed Inventory (VMI). Thus a key aspect of integration through ICT is the ability to provide real time information on product availability, inventory levels, shipment status and production requirements and allowing collaborative planning among supply chain partners by sharing information on demand forecasts, production schedules (Min \& Galle, 2003). Reconciling actual market demands (which implies wide swings due to seasonality and customer purchasing habits) with volatile demands because of amplification throughout the supply chain, requires a renewed focus on enabling information systems and technologies.

\subsection{Supply Chain Collaboration}

Supply Chain Collaboration (SCC) has raised its profile in supply chain management literature recently and is now being discussed with particular reference to ICT. Indeed, Akkermans et al., (1999) suggests that 'focusing on supply chain strategies is the next frontier in organisational excellence'. Frohlich \& Westbrook (2001) agree: the most successful manufacturers carefully link their internal processes to external suppliers and customers. Nevertheless, Ashayeri \& Kampstra (2005) suggest that successful supply chain collaborations are rare, even though SCC is now widely recognised as one of the most pressing needs in supply chain management.

In a model scenario, supply chain partners would co-operate to restructure business practices, as necessary using available technology, and provide 'customers with products and services better/faster/cheaper than ever before' Stank et al., 1999). ICT is clearly important because historically the automotive sector has relied on forecast information which creates uncertainty and is also influenced by promotions, product variety, changing demand patterns and competitive pressure. Accuracy can be improved by using real-time data (Childerhouse et al., 2003) and where information from the buyer is important to the supplier's inventory and production decision.

Gunasakaran (2005) argues the Build-to-Order Supply Chain (BOSC) is also now being actively pursued in several different industries, and describe studies that support ICT role in implementing them. Yet the adoption of these processes and technologies is problematic, and BOSC may well fail unless practical implementation and firm interoperability can be improved.

The current state of SCC ICT is well documented in the literature; however, a number of initiatives are notable. Quick Response (QR) was implemented in the 1980s in the apparel industry whereby sales data was electronically transmitted to suppliers to trigger production of new items to replenish retailers (Hunter, 1990). Efficient Consumer Response (ECR) was a response to supply chain inefficiencies (Barratt \& Oliveira. 2001), 
where the supply chain was required to transform from a 'stock-push' to a 'customerpull' system, requiring the supply chain to collaborate in order to replenish stock. The concept originates from just-in-time and just-in-sequence strategies typified by current automotive supply chains. ECR cuts costs by eliminating activities that don't add value. Continuous Replenishment Planning (CRP) shares information from the downstream stock situation regarding demand, stock and delivery times, allowing smoother flow from suppliers. The approach allows the supply chain to collaborate by substituting inventory with information (van Hezewijk \& van Assen, 2005). VMI is also a popular supply strategy that is now held in high esteem in a number of market sectors including the automotive and aerospace industries because customers often find it beneficial to 'delegate responsibility for the replenishment process to the supply chain' (Disney \& Towhill, 2003). In terms of performance, however, the key performance measure is no longer delivery time, but the availability and turnover of inventory. In a similar way, Factory Gate Pricing (FGP) transfers the responsibility and control of replenishment to the retailer with the additional advantage of reduced transportation cost for the customer. Further, the CPFR concept (Fliedner, 2003) attempts to fill some of the gaps left by previous SCM practices, such as the necessity to hold high stock levels to ensure product availability; multiple forecasts within supply chain; the link between promotions and the sales forecast; changing demand patterns and general synchronisation of supplier efforts.

Based on the VICS process model (Barratt \& Oliveira. 2001), the focus of CPFR is enhanced by encompassing planning, forecasting and replenishment processes in one package, where much of its popularity is attributable to the impressive results reported by early programs. However, CPFR takes a number of different forms across supply networks and can be a laborious process to implement, especially when supported by inadequate systems. For example, forecast reconciliation remains a frustrating, errorprone process without automated exception management. Most current solutions also fail to scale adequately as a manufacturer adds more retailers and the problem is made worse by an inability to integrate with back-end production systems. Assumptions are often made over the implementation of ICT projects as being relatively straightforward. Yet this ignores the fundamental problems of sustaining these collaborative ventures across long time periods, involving diverse stakeholders with a variety of multi-level barriers and conflicting motivations.

In summary, the literature is full of examples where IOS adoption is fraught with difficulties, from ERP implementations running over budget, to organizational objectives simply not being met. While earlier literature identifies firm level barriers to IOS adoption, this continues to evolve as new cases of failure emerge. In this research, the focus on supply responsiveness by automotive firms highlights the huge challenges faced in providing appropriate technological and social support for the project. Implementing responsive supply networks through supply chain coordination adds a new layer of complexity through which managers must navigate to ensure success. Hence, the aim of the research is to apply current knowledge of IOS barriers to emerging automotive cases seeking to achieve responsiveness, and to provide an initial framework for planning such initiatives in the future.

\section{$3 \quad$ Method}


The research examines four recent examples of failed supply chain initiatives that attempt to implement one or more aspects of collaborative planning. The research design reflects the need to deconstruct and understand the reasons why ICT projects were not meeting requirements in the automotive industry. Hence, case selection was based on known automotive initiatives in procurement, supply and operations. The investigation was based on the objective of exploring the barriers governing supply chain integration. This was operationalised through structured interviews and onsite workshops, followed by the development and analysis of a barriers framework (Figure 1). External validity was ensured through obtaining industry feedback on the initial framework and results, gained from multiple data sources (i.e. the OEMs and Suppliers within the initiative). Four supply chain initiatives were selected as examples of collaborative planning that subsequently failed to meet their original objectives. Based on interviews with senior supply chain managers at OEMs and suppliers, the research offers a multi-level framework of barriers to implementing collaborative, inter-organisational systems.

Fig 1 Process Perspective Methodology

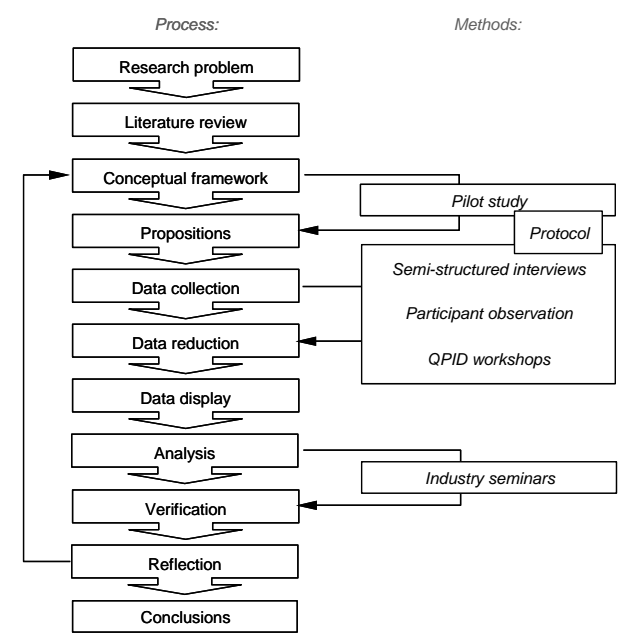

\section{$4 \quad$ Findings}

Despite the existence of a comprehensive process model allied with promising results from other sectors, widespread adoption of CPFR has not been forthcoming. This justifies a re-examination of the benefits and barriers. Barratt and Oliveira (2001) list the benefits espoused by the growing number of supporters of the CPFR process. Benefits are comprehensively discussed in the literature and would be attractive to any industry seeking clear incentives for implementation. Yet the associated barriers appear to pose considerable complexity for firms that are neither fully understood nor widely disseminated. The cases are now outlined below: 


\subsection{Covisint}

Covisint was launched during the dotcom frenzy of early 2000 as the biggest and most powerful automotive internet trade exchange or 'e-hub'. Announced as the beginning of a new era in purchasing and supply chain management, automakers poured $\$ 500$ million into the Covisint venture that was supposed to transform the automotive industry by using on-line auctions and electronic parts catalogues to drastically reduce material costs. Founder members Ford, General Motors, and DaimlerChrysler (later joined by PeugeotCitroen, Renault and Nissan) anticipated significant price reductions and customer responsiveness by combining purchasing economies of scale and Internet technology. However, rival manufacturers and suppliers were already developing their own solutions and were reluctant to join Covisint over fears of accepting a subordinate role. The vision to create an on-line industry trade exchange for both suppliers and automakers backfired due to issues over anti-trust legislation, agreement over on-line software development, and reluctance from suppliers to subscribe to a system that overnight could slash their component prices. As other trade exchanges proliferated, Covisint's vision of offering collaborative procurement, lower transaction costs, and the introduction of a universal system standard began to diminish (Helper \& McDuffie, 2003). In January 2004, the e-hub that was supposed to transform the automotive industry was disassembled and put up for sale (ANE, 2004). It is currently being restructured by an IT provider in the USA to offer on-line services in healthcare.

\subsection{Everest}

Everest was planned as private exchange that would eventually replace all Ford production and non-production purchasing systems around the world, including links to all major suppliers. In 2000, Ford procurement IT consisted mainly of mainframe legacy systems and client databases built up over a long period offering only partial visibility in the US and virtually none across Ford's Premier Automotive Group subsidiaries in Europe: Jaguar, Aston Martin, Land Rover and Volvo. The ambitious nature of Everest presented huge potential for savings where materials spending totalled around $\$ 100$ billion a year. This meant subsidiaries such as Swedish automaker Volvo was obliged to integrate a large-scale e-procurement hub into its business despite the design being based on US processes and organizational structure that was very different to its own. The scale of Everest created huge difficulties because it required compatibility not only at a technical standards level, but also adherence to common business practices. Thus, the system roll-out encountered difficulties due to internal relations with business units in different regions across the world, and fundamental issues with the supply chain. Suppliers were reluctant to participate in a system whereby buyers could take advantage of increased transparency and reverse auctions. As the original scope of the system began to be scaled back, the project was eventually abandoned.

\subsection{ICON}


The ICON Supply Chain Collaboration (SCC) tool was envisaged as a repository for the OEMs supply requirements, inventory requirements and production capacities of each supplier. The idea was to promote clear visibility between levels of the supply chain, so anticipating production difficulties and allowing optimised stocking. The ICON SCCTool algorithms boasted dynamic adjustment of inventory levels for each component to meet the upcoming production needs. Benefits for the supplier included direct access to the demands of the OEM and advice on supply problems via a 'traffic light' system. The tool was implemented by a number of automotive OEMs and their suppliers as an off-theshelf application. However, in order to meet the requirements of all the project partners, information was to be sent either via EDI, e-mail, automatically or manually to an e-mail address. Although a practical method of getting around a real problem in supply chain management, there were difficulties in implementing the full tool (in particular management of capacity information) between automotive OEMs and their suppliers, and was recently discontinued by them.

\section{$4.4 \quad$ LiNet}

Aimed primarily at the SME sector, LiNet intended to extend and harmonise the supply function by creating seamless supply management systems. LiNet commenced in 2000 as an attempt to capture the requirements of both OEM and suppliers perspectives and derive the requirements for an ideal process. This took the form of a 'Conference Room Pilot' (CRP). The collaborative effort was impressive with project partners including Audi, BMW, DaimlerChrslyer, and VW. The objective was to determine the quantitative and time-referred material requirements for the entire supply network. Demand planning was to be based on customer demands, whose data transferred by EDI. The system was designed to generate order advices for the material planning managers on the basis of primary demands. Capacity planning was to be carried out covertly by the system at each level of the supply network. The CRP was designed to transform diverse formats into a single system making it possible to handle the supply network from every level of the supply chain. LiNet was discontinued in 2003 after legal issues concerning the use of software were found to be insurmountable. Further to this, it became apparent that the standards and rules set up for the use of the Pilot could not have been transferred between customers and suppliers due to inter-organisational culture issues.

\section{Analysis and identification of barriers}

An examination of the four failed initiatives: Covisint, eVerest, ICON and LiNet shows a range of barriers that need to be addressed before commencing adoption (Table 1). Industry level barriers are represented by stakeholder dynamics involving power, legitimacy, and urgency, which mediates between the motivations to adopt information systems and the barriers against. Barriers which concern industry as a whole include the issue of resistance to e-hubs or exchanges due to the fear of price cuts, lack of trust in more powerful stakeholder groups, and the increasing burden of network complexity. Further, the competitive conflict between consortium, private, and third party e-hubs to increase membership does not address long-term concerns over adherence to universal industry standards and protocols. 
Table 1 Collaborative planning system implementation barriers (Adapted from Howard et al., 2006)

\begin{tabular}{|c|c|c|c|c|}
\hline & Covisint & eVerest & ICON & LiNet \\
\hline 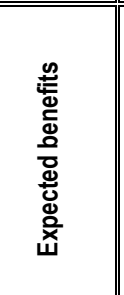 & $\begin{array}{l}\text { - } \text { Indirect price reduction } \\
\text { - } \text { Direct price reduction } \\
\text { - Minimise paper } \\
\text { - } \text { transactions } \\
\text { - } \text { - Transtronic audit capability } \\
\text { - Control maverick spending }\end{array}$ & $\begin{array}{l}\text { - } \\
\text { Reduce inventory } \\
\text { costs } \\
\text { - Increase supply chain } \\
\text { efficiency } \\
\text { - } \text { Create more strategic } \\
\text { buyers } \\
\text { - Cross-functional } \\
\text { integration } \\
\text { - Opportunity to learn } \\
\text { from Ford }\end{array}$ & $\begin{array}{l}\text { - Stock level visibility } \\
\text { across the whole } \\
\text { supply chain } \\
\text { - Capacities across } \\
\text { the supply chain }\end{array}$ & $\begin{array}{l}\text { - Optimized resource planning } \\
\text { between partners } \\
\text { - Management of critical SC } \\
\text { situation } \\
\text { - Short-term cost saving potentials } \\
\text { by reducing re-scheduling efforts, } \\
\text { urgent transports, stock levels, } \\
\text { etc. } \\
\text { - Demand-oriented and functionally } \\
\text { expandable }\end{array}$ \\
\hline \multicolumn{5}{|l|}{ Barriers } \\
\hline 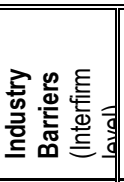 & $\begin{array}{l}\text { Supplier resistance to } \\
\text { subscribe to reverse } \\
\text { auctions and VM-owned e- } \\
\text { hubs } \\
\begin{array}{l}\text { Anti-trust } \\
\text { delaying launch }\end{array} \\
\end{array}$ & $\begin{array}{l}\text { Fears that suppliers will } \\
\text { perceive e-hub as } \\
\text { adoption of 'arms-length' } \\
\text { business practices - } \\
\text { leading to erosion of trust }\end{array}$ & $\begin{array}{l}\text { Structural } \\
\text { (standards) over come } \\
\text { through middleware data } \\
\text { reformatting }\end{array}$ & $\begin{array}{l}\text { Lack of industry-wide standardisation } \\
\text { commitment } \\
\text { Lack of industry-wide approach to } \\
\text { guarantee data security }\end{array}$ \\
\hline 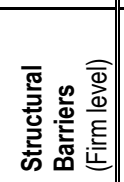 & $\begin{array}{l}\text { New systems must be } \\
\text { institutionalised to align with } \\
\text { the needs of the centralized } \\
\text { purchasing commission } \\
\text { Conflict from US \& EU firm } \\
\text { structures }\end{array}$ & $\begin{array}{l}\text { Concern over eVEREST } \\
\text { limited choice of suppliers } \\
\text { High cost of subscribing } \\
\text { to electronic catalogues }\end{array}$ & $\begin{array}{l}\text { Low cost implementation, } \\
\text { not investment, just } \\
\text { service charge }\end{array}$ & $\begin{array}{l}\text { Lack of defined approach for cost- } \\
\text { benefit sharing }\end{array}$ \\
\hline 预 琼 & $\begin{array}{l}\text { Cultural mismatch between } \\
\text { US and European offices } \\
\text { Employees acknowledge } \\
\text { that Ford is still a } \\
\text { hierarchical-style company }\end{array}$ & $\begin{array}{l}\text { Concern over Volvo's } \\
\text { unique independent } \\
\text { Swedish origins being } \\
\text { affected by American } \\
\text { process and culture }\end{array}$ & $\begin{array}{l}\text { Level of trust endured } \\
\text { after system switched off } \\
\text { Did not share capacity } \\
\text { information }\end{array}$ & $\begin{array}{l}\text { Lack of mutual trust between the } \\
\text { partners with respect to data sharing } \\
\text { and data abuse } \\
\text { Lack of the culture of creating a } \\
\text { win/win situation }\end{array}$ \\
\hline 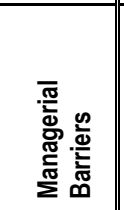 & $\begin{array}{l}\text { Resistance by managers } \\
\text { who already have } \\
\text { established purchasing } \\
\text { relationships } \\
\text { CEO leadership difficulties } \\
\text { over the management of e- } \\
\text { commerce }\end{array}$ & $\begin{array}{l}\text { Current } \text { processes } \\
\text { managed by paper and } \\
\text { personality } \\
\text { Managers fear } \\
\text { redundancy through the } \\
\text { supplier e-database }\end{array}$ & $\begin{array}{l}\text { Not a strategic process as } \\
\text { such, not used to share } \\
\text { capacity information }\end{array}$ & $\begin{array}{l}\text { Not a strategic process as such, not } \\
\text { used to share capacity information } \\
\text { Fast development in the ICT sector } \\
\text { makes the decision makers doubt } \\
\text { whether they are investing in the right } \\
\text { ICT technology or not }\end{array}$ \\
\hline 这 & $\begin{array}{l}\text { Staged implementation of } \\
\text { Covisint means it is difficult } \\
\text { to identify the system as a } \\
\text { definitive product for users } \\
\text { Operators used to bespoke } \\
\text { system design means } \\
\text { difficulties in adapting to a } \\
\text { standard package }\end{array}$ & $\begin{array}{l}\text { User fears over the effect } \\
\text { of increased transparency } \\
\text { by eVEREST restricting } \\
\text { the individual's autonomy } \\
\text { Worries over people } \\
\text { losing their own way of } \\
\text { working }\end{array}$ & $\begin{array}{l}\text { Usually identified before } \\
\text { the alert } \\
\text { Can quantify a problem, } \\
\text { but reverts to telephone to } \\
\text { resolve the problem, as } \\
\text { before ICON }\end{array}$ & $\begin{array}{l}\text { Variety of user requirements too } \\
\text { high }\end{array}$ \\
\hline 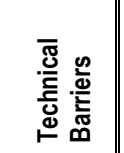 & $\begin{array}{l}\text { Decommissioning legacy } \\
\text { systems }\end{array}$ & $\begin{array}{l}\text { Multiple IT } \quad \text { legacy } \\
\text { systems }\end{array}$ & Usual website delays & $\begin{array}{l}\text { Lack of interoperable systems across } \\
\text { the SC }\end{array}$ \\
\hline
\end{tabular}

Firm level barriers are also represented by the framework. Structural alignment reflects the difficulties for firms to align e-hubs with current organizational hierarchies and the associated problems of interfacing with internal purchasing and supply systems. The cost of e-hub subscriptions and the internal human resource issue rises in proportion to the number of external networks used by the firm. Cultural differences reflect the mismatch 
in outlook between US and European businesses brought together as an attempt to create closer relations by interacting via e-hubs. This means that suppliers or manufacturers with strong associations to brand or national identity often feel that their independence is threatened by generic, automated links to other organizations. The lack of leadership by senior management is illustrated by a general poor awareness of the potential impact of the Internet and the difficulties over e-hub adoption.

User buy-in reflects the fears by people who associate the transparency of ehubs with a perceived threat to individual autonomy, supporting other recent studies (Lippert \& Foreman, 2006). Procurement and materials planning and logistics system users are often reluctant to abandon their bespoke IT systems because of the implications of retraining and the uncertainty over long-term benefits from e-hubs and the stability offered by the status quo. 'Accessibility' implies the difficulties of logging on and navigating through password-protected sites, which are often slow, complex, and provide little support for the user. Legacy IT system infrastructure represents a barrier to e-hub adoption because of the difficulties of interfacing bespoke technology to a common business standard across many organizations.

\section{Discussion}

This research represents a study of barriers which is unusual as most related research tends to be normative and prescriptive. It adopts a critical view taken from multiple perspectives within the automotive industry, showing that structural, cultural, managerial, user and technical factors need to be overcome if collaborative planning initiatives are to be successful.

Summarising the four cases; Covisint was anticipated to improve transaction efficiency and provide an electronic audit capability. It failed, primarily at the interfirm level where supplier resistance to subscribe to fixed-duration bidding events reduced willingness to collaborate. This was compounded by the inexperience of management to form a robust e-business strategy and ultimately led to resistance in establishing purchasing relationships. Everest was conceived primarily to increase supply chain efficiency and promote cross-functional integration. It failed structurally because of fears of the reduced supplier base it would support and at a user level was perceived to improve transparency a little too far, whilst restricting autonomy. Whilst ICON was envisaged to provide stock level visibility throughout the entire supply chain, it failed culturally on issues of trust allied with the systems inability to manage capacity information. In fact, the level of implementation meant that although it was a useful tool to share inventory information and provide alerts when certain thresholds were met, the strategic possibilities of the tool were not developed. In particular the possibility to monitor supply chain capacities could have provided large benefits in terms of proactively managing future shortages and responding to end customer demand and yet this function was not utilised (for reasons that cut across the barriers levels). Finally LiNet, which espoused to optimise resource planning and supply chain management, was not adopted because of the lack of industry standards combined with managerial hesitation over system and technology selection. A particular problem was the concept of cost and benefit sharing. Supply chain waste can be identified more objectively in a process where there is more visibility of information on inventory and capacity. Thus, agreements have to be made to act to reduce this waste, but this is problematic where multiple partners and sites are involved. In this case agreement was not reached between the project partners. 
This paper suggests that core issues such as system standardisation must be addressed by industry leaders as a whole, not by individual firms, in order to reduce the burgeoning demands on suppliers to support multiple interfaces. Perhaps an independent organization holds the key to closer integration of automotive information system networks? While government intervention seems a particularly blunt approach, there is at least one example: the 1980s Australian 'Button' programme, where strict central government control over EDI standards ultimately proved beneficial to the industry as a whole. The power of open structures such as the Internet make government or voluntary regulation more difficult in what is effectively an open market and may represent the only viable route for the automotive sector. Already, tier 2 and 3 suppliers are enjoying the benefits of protocols such as XML at a fraction of the cost of vehicle manufacturer and tier 1 supplier bespoke EDI systems. If the issues of Internet governance can be resolved emerging ICT such as web-EDI and collaborative platforms, these tools offer considerable benefits to the industry.

\section{Conclusions}

This paper examines the motivations and barriers to collaboration and information sharing across auto industry supply networks. It suggests that firms participating in initiatives which are web-enabled and CPFR-related must give considerable thought towards the barriers to successful collaboration, as well as benefits. The increasing requirement for responsive supply chains (e.g. build-to-order) is clearly evident, where all the cases explored in this investigation offered visions of an integrated and collaborative supply chain. Whilst the approach taken in each case appeared at the outset to be appropriate, during implementation each venture failed to deliver on core objectives. Literature continues to expound the benefits of such systems, where supply integration is largely dependant on electronic tools as enablers to interfirm collaboration. Yet in reality this is an extremely difficult task.

Our framework highlights the significant level of user, managerial, cultural and structural barriers associated with large scale 'big bang' ICT projects. It refocuses attention to the interfirm or industry level barriers, such as supply chain resistance because of lack of resource to support new systems, and the lack of adherence to universal industry ICT standards. In their attempt to emulate more information-intensive sectors such as FMCG, automakers and (to a lesser extent) their partners seem to have lost sight of the core values which make up organisational culture, structure and buyersupplier relationships. The framework therefore presents a practical perspective on ICT implementation for responsive automotive networks, with lessons which may apply to other manufacturing industries struggling to gain profitability in the $21^{\text {st }}$ century. Future research seeks to explore the issues of regulating information system standards, and the role of trust in e-procurement. In automotive as in other industries, resolving these challenges means the industry as a whole must examines its current processes, whereby the views of all stakeholders (not just the most powerful) are considered in order to achieve greater levels of harmony across the network.

\section{References}

Akkermans H, Bogerd P, Yucesan E, Van Wassenhove L. (1999). The Impact of ERP on Supply Chain Management: Exploratory Findings from a European Delphi Study, INSEAD. (1999): Fontainebleau, France

ANE. 2004. A decimated Covisint is put up for sale., Automotive News Europe: 17 
Ashayeri J, Kampstra R. (2005). Realities of Supply Chain Collaboration, Euroma Operations and Global Competitivenenss: Budapest, Hungary

Barratt M, Oliveira A. (2001). Exploring the Experiences of Collaborative Planning Initiatives. International Journal of Physical Distribution and Logistics Management 31(4): 266-289

Barret S, Konsynski B. (1982). Inter-Organisational Information Sharing Systems. MIS Quarterly. Special Issue: 93-105

Bowersox DJ, Closs DJ. (1996). Logistical Management: The Integrated Supply Chain Process. McGraw-Hill: New York

Childerhouse P, Hermiz R, Mason-Jones R, Popp A, Towill DR. (2003). Information flow in automotive supply chains $\sim$ An assessment of present industrial practice. Journal of Industrial Management and Data Systems 103(3): 137-149

Christopher M. (1999). Global Supply-Chain: The Role of Agility. Logistics Focus (September): 28-30

Ciborra C. (1993). Teams, Markets and Systems - Business innovation and information technology. Cambridge University Press

Clemons E, Row M. 1992. Information technology and industrial cooperation: the changing economics of cooperation and ownership. Journal of Management Information Systems 9(2): 9-28

Disney S, Towill D. (2003). The effect of vendor managed inventory (VMI) dynamics on the Bullwhip Effect in supply chains. Int. J. Production Economics 85: 199-215

Duclos LK, Vokurka RJ, Lummus RR. (2003). A conceptual model of supply chain flexibility. Industrial Management and Data Systems 103(6): 446-456

Earl M. (1989). Management Strategies for Information Technology. P. Prentice Hall,: London.

Economist. (2004a). Car Manufacturing - Ripe for Revolution, Economist:

Economist. (2004b). E-commerce takes off, Economist:

Fisher ML. (1997). What is the Right Supply Chain for your Product? Harvard Business Review 75, March-April(2): 105-116

Fliedner G. (2003). CPFR: an emerging supply chain tool. Industrial Management \& Data Systems 103(1): 14-21

Frohlich MT, Westbrook R. (2001). Arcs of integration: an international study of supply chain strategies. Journal of Operations Management 19: 185-200

Gunasakaran A. (2005). The Build-to-order supply chain (BOSC): a competitive strategy for the 21st century. Journal of Operationas Management 23: 419-422

Hart P, Saunders C. (1997). Power and Trust: Critical factors in the Adoption and Use of Electronic Data Interchange. Organization Science. 8(1): 23-42.

Helper S, MacDuffie J. (2003). B2B and Modes of Exchange: Evolutionary and Transformative Effects. In Kogut, B. (Ed) The Global Internet Economy. Wharton Business School

Holweg M. (2005). An investigation into supplier responsiveness: Empirical evidence from the automotive industry. International Journal of Logistics Management 16(1): 96-119

Howard M, Vidgen R, Powell P (2006). Automotive e-Hubs: Exploring Motivations and Barriers to Collaboration and Interaction. Journal of Strategic Information Systems. 15 (1). 51-75

Howard M, Vidgen R, Powell P (2006). Overcoming Stakeholder Barriers in the Automotive Industry: Building to Order with Extra-Organizational Systems. Journal of Information Technology 18(1): 27-43

Hunter A. (1990). Quick Response in Apparel Manufacturing. The Textile Institute: Manchester 
Ives B, Learmonth G. (1984). The Information System as a Competitive Weapon. Communications of the ACM 27: 1193 -1201.

Konsynski B, McFarlan W. (1990). Information partnerships - shared data, shared scale. Harvard Business Review: 114 -120

Krajewski L, Wei JC, Tang L-L. (2005). Responding to schedule changes in build-toorder supply chains. Journal of Operations Management 23(5): 452-469

Kumar K, van Dissel H. (1996). Sustainable collaboration: managing conflict and cooperation in interorganizational systems. MIS Quarterly 20(3): 279-307

Kwon K, Zmud R. (1987). Unifying the Fragmented Models of Information Systems Implementation. In: Boland, R. J., \& Hirschheim, R. A. Critical Issues in Information Systems Research.

Lapidus G. (2000). Gentlemen, Start Your Search Engines. Goldman Sachs Research

Lee HL, Padmanabhan V, Seungjin W. (1997). The Bullwhip Effect in Supply Chains. Sloan Management Review 38(3): 93-102

Lippert, S.K. and Forman, H. (2006) A supply chain study of technology trust and antecedents to technology internalization consequences International Journal of Physical Logistics and Distribution Management, 36(4): 271-288.

Min H, Galle WP. 2003. E-purchasing: profiles of adopters and nonadopters. Industrial Marketing Management 32(3): 227-233

Mukhopadhyay T, Kekre, Kalathur. (1995). Business value of information technology: a study of electronic data interchange. MIS Quarterly 19: 137-156

Porter M, Millar V. (1985). How information gives you competitive advantage. . Harvard Business Review: 149-160

Presutti W. (2003). Supply management and e-procurement: creating value added in the supply chain. Industrial Marketing Management 32: 219-226

Smith L. 2006. West Marine: A CPFR Success Story, Supply Chain Management Review, http://www.manufacturing.net/scm/article/CA6317964.html:

Stank TP, Daugherty PJ, Autry CW. (1999). Collaborative planning: supporting automatic replenishment programs. Supply Chain Management 4(2): 75-85

Tachizawa EM, Gimenez C. (2005). An empirical investigation on supply flexibility. In K Demeter (Ed.), European Operations Management Association: 1729-1738: Budapest

Tapscott D, Ticoll D, Lowy A. (2000). Digital Capital: Harnessing the Power of Business Webs. Nicholas Brealey.: London

van Hezewijk B, van Assen M. (2005). Coordination in Chains and Networks, Euroma Operations and Global Competitiveness: Budapest , Hungary

Vance A. (2003). SAP costs too much - customers: www.theregister.co.uk

Webster J. (1995). Networks of collaboration or conflict? Electronic data interchange and power in the supply chain. Journal of Strategic Information Systems 4(1): 31-42 